had to complain of the slightest rudeness nor even neglect. Every friend who has been present at a lecture, has expressed to me his admiration of the constant silence and deep attention of the class, and remarked, that they indeed de-served the name of students; the written answers of many at the sessional examination surprised me, and were worthr of established physicians. 1 therefore say only to you. go on,-Macti virtute, - and after a few years lise University of London will be spoken of throughout Europe as one of the most splendid ornaments of the British isles.

[At the conclusion of the addiress, the densely-crowded theatre resounded with accianations, and the learned professor retired amidst a deafening round of plaudits and cheers.]

\section{EMPLOYMENT OF}

\section{NARCOTINE IN AGUE.}

\section{To the Editor of THr LANCET.}

Sin, - Having observed, in the last $\mathrm{Num}$. ber of TuE LaNCET, that Dr. lioots had successfully treated three cases of ague with narcotine, and observing also his re. quest that his professional brethren would stale their experience of the remedy, I take up my pen with pleasure to corroborate his statemem, having since $13 \% 3$ tried it in variuus forms; and in 18\%8, when I had frequent cases of ague on the banks of the Thames, I found it very efficacious. But the paroxysms were very apt to return, if the medicine was discontinued too soon, or wias not followed up with a nutritious diet. My plan was (atter giving one or two doses of calomel and rhubarb) 10 administer two grains of narcotine dissolved in twenty

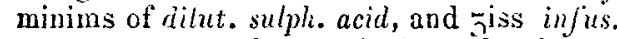
rose every two hours during the intermission, and it frequently iurested the disease at once. In one family at Aston, where the father and daughter were both suffering from ague, I, on the 23rd of August 1828, treated the father with sulphate of quinine, and the laughter with narcotine. The latter (tn adult) never had a retum of the paroxysm, but the father continued to experience his, every second day for the first week; I then gave him the narcotine, and both patients were discliarged cured before the end of the second week.

I was led io try the sulphate of narcotine on myself as a tonic, in the first place, from its similarity of taste to quinine; but the bitter is more intense. As many of your readers may feel inclined to repeat these experiments, I shall feel obliged if you will have the goodness to insert in one of your subsequent numbers, the following cheap and easy way of preparing the salts of npium, morphia, narcotine, and also the black drop, which I have used very beneficially for the last ten years.

Take two ounces of English opium; dissolve in four ounces of distilled vinegar and a pint of water; filter the solution, and add liquor ammonia sufficient to saturate the solution; let it remain in the bottom till the principle his subsided, and then pour off the clear fluid. Fill up the bottle with distilled water to wash the precipitate, and, after it has subsided, decant the supernatant fluid. To the precipitate, now add in excess a sufficient quantity of weak distilled vinegar to neutralise the morphia, and dilute the solution with six ounces of water. Allow it to remain at rest twentyfour hours, and pour off the acetate of morphia. To the remaining undissolved precipitate, add three drachms of dilute sulphuric acid, and dilute with six ounces of water, and filter. Neutralise the solution with liq. animnnia, and set aside for a day or two for the precipitate to subside. From the acetic solution you will obtain a very large quantity ot minute crystals of morphia, and from the sulphuric solution narcotine. I have found, from repeated experiments, that cold, weak, actic acid, will not dissolve nurcotine, but morphia in large quintities. These salts can be easily purified by dissolving them in boiling alkali, which, on cooling, will aftord very tine crystals.

To make the black drop-evaporate the two first solutions (after separating the precipitate), with two drachms of distilled vinegar, to the consistence of a syrup, and bottle it for use. It is necessiry to add the vinegar to prevent a further deposit of morphia as the fluid evaporates. The revidunm of the opium, and also the residue after making the tincture of opium, it boiled in water containing one drachm of sulphuic acid to the pint, will produce a lirge supply of narcotine, and also some morphia, by being treated with ammonia.

'The names of the persons cured of ague by narcotine at Aston, are William and Ann Livelsood. I bave the honour to remain, Sir, Your most obedient servant,

Thomas Wood Jiston, Surg,,

Late of the 36 th Regiment of Fout.

P.S. A quarter of an acre of land cultirated with popries on $\mathrm{mr}$ plan, as related in the Hist volume of the 'Transactions of the sionely of Arts, will affurd an ample supply of opiun for every private practitioner. 